\title{
Pico da carreira desportiva em nadadores de nível mundial: análise das idades dos participantes nos Jogos Olímpicos de Pequim 2008
}

\author{
Peak career in world-ranked swimmers: age's analysis of 2008 Beijing \\ Olympic Games participants
}

\author{
T.M. Barbosa, M.J. Costa, E. Mejias, D.A. Marinho, H. Louro, A.J. Silva
}

ARTIGO ORIGINAL | ORIGINAL ARTICLE

\begin{abstract}
RESUMO
Foi objetivo deste trabalho efetuar: (i) uma análise descritiva das idades de todos os participantes nas provas de Natação Pura Desportiva nos Jogos Olímpicos de Pequim 2008 e; (ii) uma análise comparativa das idades com base no sexo. Foram analisadas 1101 inscrições (588 masculinas e 513 femininas) em todas as provas dos Jogos Olímpicos de Pequim 2008: 50 metros livres (L50), 100 metros livres (L100), 200 metros livres (L200), 400 metros livres (L400), 800 metros livres (L800, apenas sexo feminino) 1500 metros livres (L1500, apenas sexo masculino), 100 metros costas (C100), 200 metros costas (C200), 100 metros bruços (B100), 200 metros bruços (B200), 100 metros mariposa (M100), 200 metros mariposa (M200). Foram consultadas as listas finais de resultados disponibilizadas no site oficial dos Jogos Olímpicos de Pequim 2008 para identificação das identidades e idade cronológica dos nadadores. A idade cronológica (dia, mês, ano) foi convertida em idade decimal no dia de realização das eliminatórias de cada prova. Da análise quartílica, verifica-se uma tendência para a mediana da idade decimal, bem como a variância, diminuírem com o aumento da distância nadada em todos os estilos em ambos os sexos. Verificaram-se variações significativas de acordo com o sexo na idade decimal nas provas de L400 $(p=.01)$, L1500/L800 $(p=.02)$, C100 $(p<.01)$, C200 $(p<.01)$, B100 $(p=$ $.02)$, B200 $(p=.04)$, M100 $(p=.05)$ e M200 $(p<.01)$. Em todos esses casos, a idade decimal foi significativamente superior nos nadadores do que nas nadadoras.
\end{abstract}

Palavras-chave: natação, performance, idade decimal, competição

ABSTRACT

The aim of this paper was to: (i) describe the Beijing 2008 Olympic Games swimmer's ages and; (ii) compare ages according to swimmer's gender. It was analyzed 1101 inscriptions (588 men and 513 women) for all swimming events held at the Beijing 2008 Olympic Games: 50 meters freestyle (L50), 100 meters freestyle (L100), 200 meters freestyle (L200), 400 meters freestyle (L400), 800 meters freestyle (L800, only women) 1500 meters freestyle (L1500, only men), 100 meters backstroke (C100), 200 meters backstroke (C200), 100 meters breaststroke (B100), 200 meters breaststroke (B200), 100 meters butterfly (M100), 200 meters butterfly (M200). The final result lists was consulted at the Beijing 2008 Olympic Games official internet site, collecting the swimmer's name and chronological age for each event. Afterwards, chronological age was converted into decimal age at the day of the event heats. From the quartile analysis became clear that there was a tendency for the age median and variance to decrease from the shorter to the longest events for both genders. There were significant variations in the age, according to gender at the L400 $(p=.01)$, L1500/L800 $(p=.02), \mathrm{C} 100(p<.01), \mathrm{C} 200$ ( $p<.01)$, B100 $(p=.02), \mathrm{B} 200(p=.04), \mathrm{M} 100(p=.05)$ and M200 $(p<.01)$. For all these events, decimal age was higher for men than for women.

Keywords: swimming, performance, decimal age, competition

Submetido: 07.09.2011 | Aceite: 07.12.2012

Tiago M. Barbosa. Nanyang Technological University, Singapura.

Mário J. Costa e Erik Mejias. Centro de Investigacao em Desporto, Saúde e Desenvolvimento Humano, Vila Real, Portugal.

Daniel A. Marinho. Universidade da Beira Interior, Covilhã, Portugal.

Hugo Louro. Escola Superior de Desporto de Rio Maior, Rio Maior Portugal.

António J. Silva. Universidade de Trás-os-Montes e Alto Douro, Vila Real, Portugal.

Endereço para correspondência: Tiago M. Barbosa, Physical Education \& Sports Science Academic Group, National Institute of Education, Nanyang Technological University, NIE5-03-31, 1 Nanyang Walk, Singapore 637616.

E-mail: tiago.barbosa@nie.edu.sg 
A Natação Pura Desportiva é um desporto condicionado por diversos fatores, onde os pressupostos fisiológicos e os biomecânicos têm um peso determinante na performance (Barbosa et al., 2009; 2010). Talvez por esses motivos, o início da carreira desportiva na modalidade seja, por vezes, considerada como se dando precocemente. Com efeito, a temática da especialização precoce foi particularmente focada nos debates sobre treino desportivo nos anos oitenta e noventa (Personne, 1987). Essas discussões incidiram de forma acérrima nas chamadas modalidades cíclicas e fechadas como é o caso da Natação Pura Desportiva (Makarenko, 2001; Platonov \& Fessenko, 1994; Wilke \& Madsen, 1990).

A esta ideia da precocidade do início da carreira desportiva em Natação Pura Desportiva, aglutinou-se uma outra: A precocidade com que se atinge o pico de performance, quando balizada pela carreira desportiva planeada. De uma forma prosaica, não foi raro considerar-se que os praticantes de Natação Pura Desportiva atingem o pico da carreira desportiva mais cedo do que noutras modalidades desportivas (Platonov \& Fessenko, 1994; Silva et al., 2006; Silva et al., 2007). Isto apesar de, pelo menos a idade dos finalistas nas provas olímpicas de Natação Pura Desportiva dos anos oitenta, não serem diferentes dos restantes desportos (Lavoie \& Montpetit, 1986).

Lavoie e Montpetit (1986) descreveram as idades dos participantes nas quatro edições dos Jogos Olímpicos realizados entre 1964 e 1980. Em ambos os sexos houve uma tendência de aumento da idade, passando de $19.9 \pm 0.96$ anos para $20.6 \pm 0.91$ anos para os nadadores e de $17.3 \pm 0.97$ anos para $17.8 \pm 0.97$ anos para as nadadoras durante esse período. Numa outra perspetiva, Platonov e Fessenko (1994) postularam que as idades para obtenção das melhores marcas estavam relacionadas com o sexo e a distância nadada. Nas provas de 100 e 200 metros a maioria dos homens apresentou-se com idades compreendidas entre os 18 e os
22 anos (79.5\%), no caso das mulheres entre os 16 e os 20 anos (50\%). Nas provas mais longas (i.e., 400, 800 e 1500 metros), os nadadores apresentaram entre os 17 e os 20 anos (56.7\%) e as nadadoras entre os 15 e os 18 anos (70.8\%). Weineck (2002) apresentou a evolução dos tempos dos nadadores de $100 \mathrm{~m}$ Livres durante os anos setenta, sugerindo que a idade de pico de performance foi aproximadamente os 22 anos.

As competições mais importantes a nível internacional são as mais apropriadas para se analisar o momento do pico de carreira desportiva dos nadadores de elite. Os Jogos Olímpicos são a competição mais importante e onde a larga maioria dos nadadores de nível mundial procura atingir o pico de forma no quadro de um planeamento e periodização da carreira desportiva (Maglischo, 2003). Com efeito, o próprio processo de identificação de talentos assenta num modelo operativo que toma em consideração este facto (Silva et al. 2010). Mais ainda, a idade previsível para obtenção dos melhores resultados é um tópico de interesse para os envolvidos em Natação Pura Desportiva (Silva et al., 2006; Silva et al., 2007). Silva et al. (2006; 2007) analisaram a evolução da carreira em nadadores portugueses do sexo masculino e feminino, respetivamente, utilizando modelações matemáticas. Com base na análise dos resultados obtidos, foi possível verificar que, em Portugal, tanto os nadadores como as nadadoras tendem a obter as suas melhores marcas mais cedo quanto mais longa for a distância da prova. Isto apesar das nadadoras atingirem as melhores marcas mais cedo do que os nadadores (provas de $100 \mathrm{~m}: 19.00$ vs. 21.98 anos, provas de $200 \mathrm{~m}: 18,11$ vs. 20,82 anos, 400 m: 17.44 vs. 20.66 anos) (Silva et al., 2006; 2007). Com efeito, estes resultados parecem corroborar a tendência internacional (Ivkovic, Bojanic \& Ivkovic, 2001; Sambanis, Kofotolis, Kalogeropoulou, Noussios, Sambanis \& Kalogeropoulos, 2003; Stafford, 2005). A maior precocidade das nadadoras face aos nadadores 
será explicável pelo facto de também elas apresentarem uma maior precocidade do ponto de vista da maturação biológica. Contudo, salvo melhor opinião, não parece que exista na literatura qualquer trabalho revisitando ou atualizando os estudos citados anteriormente sobre a idade de pico de carreira desportiva em nadadores de elevado nível competitivo.

No que se refere às idades ótimas de obtenção dos resultados desportivos, Silva et al. (2006) apela à necessidade da estruturação racional da preparação da carreira desportiva, visando o alcance dos melhores resultados desportivos, justificando-se a alteração da estrutura de programação desportiva a longo e médio prazo, de tal forma que: (i) a estrutura do processo de treino esteja em estreita correspondência com as particularidades individuais dos nadadores (velocistas, meio-fundistas e fundistas); (ii) se verifique um redirecionamento da orientação dos conteúdos de treino e sua magnitude, face aos condicionalismos existentes e; (iii) sejam viabilizadas medidas de promoção e enquadramento institucional especiais face à especificidade da preparação desportiva.

Desde logo emerge a questão se na entrada da segunda década do século XXI, a perspetiva de precocidade no alcance do pico de carreira desportiva em Natação Pura se mantêm, como postulado nas décadas anteriores. Mais ainda, sendo a Natação Pura uma das modalidades desportivas com uma maior mutabilidade nos anos recentes, expressa pela facilidade e quantidade de recordes do mundo batidos, faz com que o conhecimento da idade de pico de carreira permite aos treinadores de escalões de formação e de escalões absolutos balizar e definir uma plano de carreira otimizado para que os seus nadadores atinjam também eles o pico na idade adequada. Assim, visa-se fornecer aos técnicos no terreno informações úteis e da máxima relevância para a maximização do rendimento dos seus nadadores.

Foi objetivo deste trabalho efetuar: (i) uma análise descritiva das idades de todos os participantes nas provas de Natação Pura Desportiva nos Jogos Olímpicos de Pequim 2008 e; (ii) uma análise comparativa das idades com base no sexo. Definiu-se como hipóteses que os nadadores das provas mais curtas seriam mais velhos do que os das provas mais longas e, que os nadadores seriam mais velhos do que as nadadoras.

\section{MÉTODO}

\section{Amostra}

Foram analisadas 1101 inscrições (588 masculinas e 513 femininas) em todas as provas dos Jogos Olímpicos de Pequim 2008. No caso das provas masculinas de 50 metros livres (L50), 100 metros livres (L100), 200 metros livres (L200), 400 metros livres (L400), 1500 metros livres (L1500), 100 metros costas (C100), 200 metros costas (C200), 100 metros bruços (B100), 200 metros bruços (B200), 100 metros mariposa (M100) e 200 metros mariposa (M200) inscreveram-se respetivamente 97, 64, 55, 36, 35, 45, 40, 64, 52, 65 e 45 nadadores. Nas competições femininas nas provas de L50, L100, L200, L400, 800 metros livres (L800), C100, C200, B100, B200, M100 e M200 foram inscritas respetivamente 90,48 , $46,41,35,47,34,50,40,48$ e 34 nadadoras.

\section{Instrumentos e Procedimentos}

\section{Identificação dos nadadores}

Considerou-se como fator de inclusão o sujeito: (i) participar nos Jogos Olímpicos de Pequim 2008; (ii) estar inscrito em pelo menos uma prova do calendário olímpico de Natação Pura Desportiva; (iii) a inscrição ter sido efetuada pelo respetivo Comité Olímpico nacional com base em tempos mínimos de admissão, competições eliminatórias de nível nacional (i.e. National Trials) ou através de admissão livre (i.e., Wild cards) previstos em casos particulares pelo Comité Olímpico Internacional; (iv) o site oficial da competição disponibilizar cumulativamente a classificação final, 
a identificação do nadador e a sua idade cronológica (dia, mês e ano de nascimento), o tempo de prova, bem como, a data de realização das eliminatórias (dia, mês e ano).

Para identificação das identidades, idade cronológica (ano, mês e dia de nascimento) e respetiva classificação final dos nadadores em cada prova nadada, recorreu-se às listas finais de resultados disponibilizadas no site oficial dos Jogos Olímpicos de Pequim 2008 (http:// results.beijing2008.cn) acedidos em junho de 2009.

\section{Cálculo da idade decimal}

A idade cronológica foi convertida em idade decimal. O cálculo da idade decimal foi efetuada de acordo com o procedimento largamente difundido na literatura (Brown, \& Barrett, 1969; Markuske, 1971) em que:

idade decimal $=\frac{D A-D N}{365,25}$

Onde DA é a data de avaliação e DN a data do nascimento. O cálculo da idade decimal também é adotado em determinados tipos de investigações em Natação Pura Desportiva (Taylor, Stratton, Lees, Atkinson \& MacLaren, 2001). A idade decimal de cada nadador foi calculada considerando como DA o dia das eliminatórias das provas em que se encontrava inscrito. Todas as eliminatórias das provas decorreram entre os dias 09 e 15 de agosto de 2008.

\section{Análise Estatística}

A análise exploratória dos dados incluiu a determinação dos pressupostos de normalidade através do teste de Shapiro-Wilk, testando a hipótese nula que os dados selecionados têm uma distribuição normal. Foram calculadas diversas estatísticas descritivas (média, 1 desvio-padrão, variância, quartis) para todas as provas de Natação Pura Desportiva do calen- dário olímpico em ambos os sexos. Para análise da variância das idades decimais entre sexos para cada prova recorreu-se à ANOVA a um fator (sexo: masculino vs feminino). Em todas as situações o nível de significância foi determinado para $p \leq .05$.

\section{RESULTADOS}

As figuras 1 e 2 apresentam respetivamente os boxplot simples para distribuição quartílica das idades decimais de todas as provas masculinas e femininas em estudo. Em ambos os casos verifica-se uma tendência para a mediana da idade decimal, bem como a variância, diminuírem ligeiramente com o aumento da distância nadada em todos os estilos. Para as provas masculinas de L50, L100, L200, L400 e L800 a variância foi de $20.34,13.70,12.37$, 11.47 e 15.59. A variância foi de $27.26,17.81$, $11.33,10.03$ e 13.11 para as provas femininas de L50, L100, L200, L400 e L800 respetivamente.

A tabela 1 apresenta as médias e os desvios-padrão das idades decimais de ambos os sexos. Para o sexo masculino, a prova onde os nadadores inscritos apresentaram uma média de idades mais reduzida foi a L200 (22.53 \pm 3.51 anos) e mais elevada a C100 (24.29 \pm 3.70 anos). Para o caso do sexo feminino, a prova com a média etária mais reduzida foi a C200 (20.43 \pm 2.93 anos) e a mais elevada a M100 $(22.61 \pm 4.05$ anos).

A tabela 2 descreve a análise da variância das idades decimais entre as mesmas provas entre os dois sexos. No caso da distância mais longa no estilo livre, optou-se pela comparação entre a L1500 do sexo masculino com a L800 do sexo feminino. Verificaram-se variações significativas na idade decimal nas provas de L400, L1500/L800, C100, C200, B100, B200, M100 e M200. Em todos estes casos, a idade decimal foi significativamente superior nos nadadores do que nas nadadoras. 


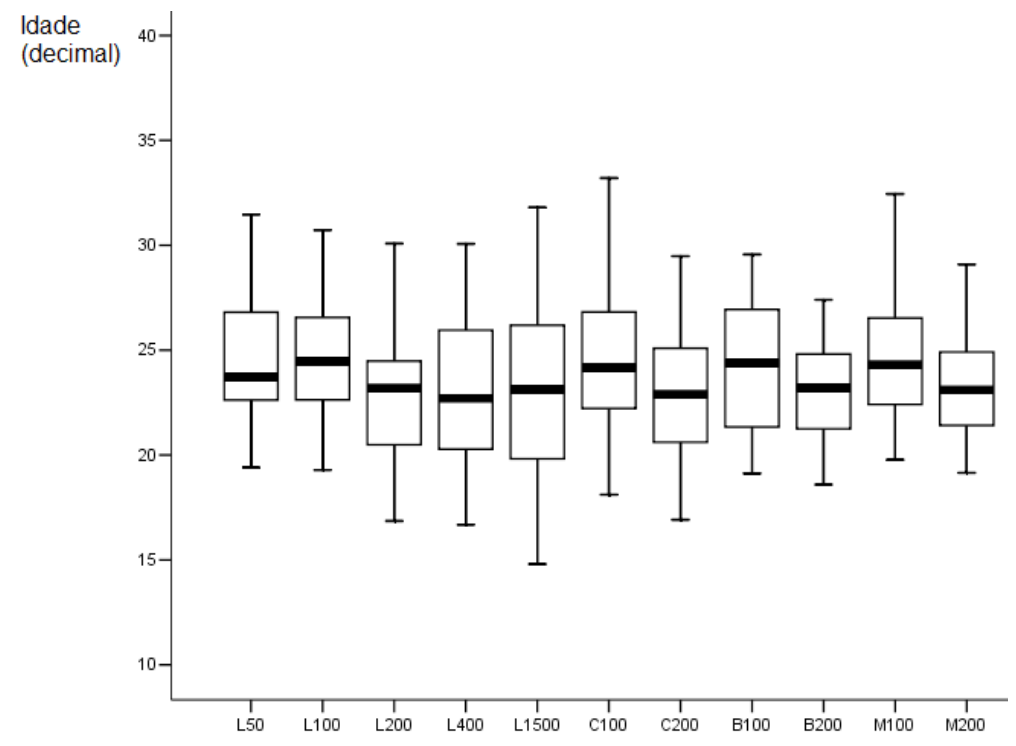

Figura 1. Percentis das idades decimais dos participantes masculinos nas provas de Natação Pura Desportiva nos Jogos Olímpicos de Pequim 2008.

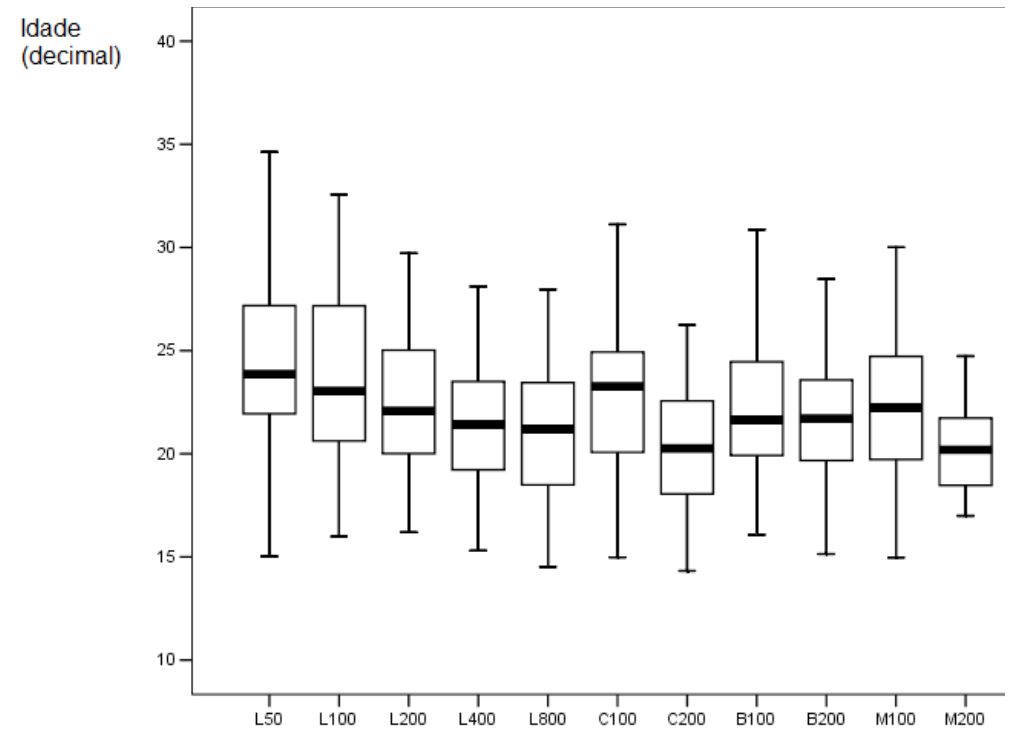

Figura 2. Percentis das idades decimais das participantes femininas nas provas de Natação Pura Desportiva nos Jogos Olímpicos de Pequim 2008.

Tabela 1.

Média e 1 desvio-padrão das idades decimais de ambos os sexos nas provas de Natação Pura Desportiva dos Jogos Olímpicos de Pequim 2008.

\begin{tabular}{ccc}
\hline & $\begin{array}{c}\text { Sexo masculino } \\
\text { (idade decimal) }\end{array}$ & $\begin{array}{c}\text { Sexo feminino } \\
\text { (idade decimal) }\end{array}$ \\
\hline L50 & $22.99 \pm 4.51$ & $22.31 \pm 5.22$ \\
L100 & $24.06 \pm 3.70$ & $22.83 \pm 4.22$ \\
L200 & $22.53 \pm 3.51$ & $21.86 \pm 3.36$ \\
L400 & $23.19 \pm 3.38$ & $21.30 \pm 3.16$ \\
L800/L1500 & $23.20 \pm 3.94$ & $21.04 \pm 3.62$ \\
C100 & $24.29 \pm 3.70$ & $21.84 \pm 4.20$ \\
C200 & $23.03 \pm 3.75$ & $20.43 \pm 2.93$ \\
B100 & $23.22 \pm 3.51$ & $21.63 \pm 3.37$ \\
B200 & $22.96 \pm 2.75$ & $21.60 \pm 3.43$ \\
M100 & $24.01 \pm 3.43$ & $22.61 \pm 4.05$ \\
M200 & $23.57 \pm 3.40$ & $20.87 \pm 3.24$ \\
\hline
\end{tabular}

Tabela 2.

Análise da variância das idades decimais entre sexos.

\begin{tabular}{cccc}
\hline & $\begin{array}{c}\text { Graus de } \\
\text { liberdade }\end{array}$ & F de Fisher & Valor de $p$ \\
\hline L50 & 1.182 & 0.887 & $.35(\mathrm{NS})$ \\
L100 & 1.111 & 2.676 & $.11(\mathrm{NS})$ \\
L200 & 1.101 & 0.940 & $.34(\mathrm{NS})$ \\
L400 & 1.77 & 6.435 & .01 \\
L1500/L800 & 1.70 & 5.640 & .02 \\
C100 & 1.92 & 8.572 & $<.01$ \\
C200 & 1.74 & 10.777 & $<.01$ \\
B100 & 1.112 & 5.793 & .02 \\
B200 & 1.92 & 4.436 & .04 \\
M100 & 1.113 & 3.931 & .05 \\
M200 & 1.78 & 12.542 & $<.01$ \\
\hline
\end{tabular}




\section{DISCUSSÃO}

O presente estudo teve como objetivo realizar uma análise descritiva das idades de todos os participantes nas provas de Natação Pura Desportiva nos Jogos Olímpicos de Pequim 2008 e uma comparação das mesmas com base no sexo. Constatou-se que existe uma tendência para os nadadores das provas mais curtas serem mais velhos do que os das provas mais longas em ambos os sexos, e os nadadores serem mais velhos do que as nadadoras.

Verifica-se uma tendência para a mediana da idade decimal diminuir ligeiramente com o aumento da distância nadada em todos os estilos nos dois sexos. Na realidade, alguns autores estudaram outras variáveis de tendência central que não a mediana. Antes, optaram pela média (Lavoie \& Montpetit, 1986; Platonov \& Fessenko, 1994) ou a moda (Platonov \& Fessenko, 1994; Weineck, 2002). Todavia, dada a natureza do estudo em causa, parece ser mais pertinente averiguar a mediana das idades, já que esta indica até que idade decimal se encontravam $50 \%$ dos nadadores(as) participantes em cada prova do calendário olímpico (i.e. o percentil 50). A adoção exclusiva quer da média, quer a moda, implicava uma análise de variáveis de dispersão. Desta forma, optou-se pela descrição dos valores de mediana, média e desvio-padrão.

A figura 3 apresenta a comparação do pico que carreira dos nadadores olímpicos aqui analisados com a previsão efetuada para nadadores portugueses dos sexo masculino (Silva et al., 2006) e sexo feminino (Silva et al., 2007). $\mathrm{Da}$ comparação transparece que, de forma genérica, o pico de forma na realidade portuguesa ocorre mais cedo do que nos nadadores olímpicos. Este facto pode estar associado a questões mais de índole sócio-cultural e não tanto do treino desportivo propriamente dito. A realidade da natação portuguesa é distinta da verificada nos países que são potências da natação mundial. Em Portugal os nadadores não são semiprofissionais nem tão pouco se dedicam a cem por cento à modalidade. A prática da Natação Pura faz-se em articulação com outras atividades como a académica ou a laboral. Consequentemente, a entrada para o ensino superior por volta dos 18 a 20 anos leva a que uma parte substancial dos nadadores ou abandone a modalidade ou lhe passe a dedicar menos tempo. Seria interessante uma reflexão análoga para outras realidades como a brasileira, a angolana, a moçambicana ou qualquer outro dos PALOPs. Todavia, salvo melhor opinião não existe na literatura qualquer estudo a este respeito. O mais próximo foi o estudo de Darido e Farinha (1995) que verificaram na realidade brasileira um abandono da modalidade entre os 17 e os 21 anos. Este facto parece ser similar à realidade portuguesa como descrito anteriormente.

Lavoie e Montpetit (1986) descreveram que as idades dos participantes nas quatro edições dos Jogos Olímpicos entre 1964 e 1980 variaram entre os $19.9 \pm 0.96$ anos para os $20.6 \pm 0.91$ anos no caso dos nadadores e dos $17.3 \pm 0.97$ anos para os $17.8 \pm 0.97$ anos no caso das nadadoras. Tentando uma comparação mais "qualitativa" dos dados destes dois autores com os do presente estudo, parece que os nadadores de elite do século XXI são claramente mais velhos do que os dos anos 60, 70 e 80 do século XX. Mais ainda, alguns autores tendiam a sugerir que a idade de pico de forma da carreira seria atingida bem mais cedo do que se verifica hoje em dia (Platonov \& Fessenko, 1994; Weineck, 2002). Todavia, pode acontecer que a idade em que se atinja o pico de carreira, aconteça dentro dos limites balizados pela literatura. Diversos autores consideram esse facto, não só no contexto da natação Portuguesa (Silva et al., 2006; 2007) mas também da natação internacional (Ivkovic, Bojanic, \& Ivkovic, 2001; Sambanis, Kofotolis, Kalogeropoulou, Noussios, Sambanis, \& Kalogeropoulos, 2003; Stafford, 2005). Assim, poder-se-á especular que apesar da idade de obtenção do pico de carreira não se ter alterado de forma decisiva, 

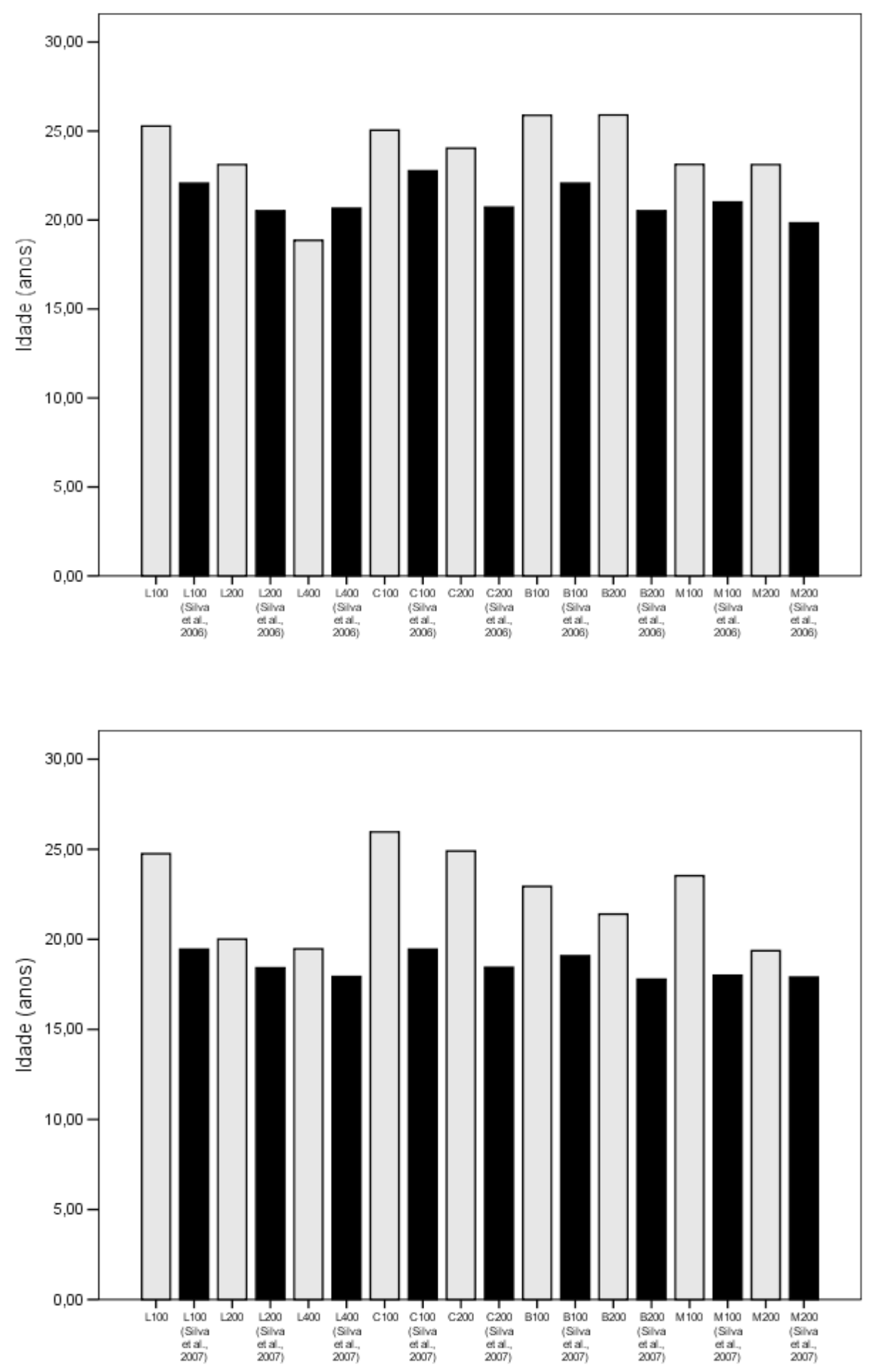

Figura 3. Comparação do pico de carreira dos nadadores participantes nos Jogos Olímpicos de Pequim 2008 com os nadadores portugueses do sexo masculino (Silva et al., 2006) e do sexo feminino (Silva et al., 2007).

o que possibilitou aos nadadores manterem-se durante mais tempo ao mais alto nível competitivo.

Esta manutenção durante mais tempo em competições de nível internacional pode ser constatada pela análise da variância das idades decimais. No atual estudo constatou-se uma tendência para a variância diminuir com o aumento da distância do nado em todos os estilos em ambos os sexos. A maior variância 
nas provas mais curtas será explicada pela participação nessas provas de nadadores(as) de idades mais avançadas, o que aumenta a variância e o desvio-padrão. Não se querendo fazer generalizações a partir de casos particulares, foi particularmente mediática a participação em finais olímpicas de alguns nadadores, de ambos os sexos, na casa dos trinta e muitos anos conseguindo obter em alguns casos lugares no pódio. Este prolongar da carreira desportiva parece ser uma premência dos debates decorridos nos anos oitenta e noventa sobre a especialização precoce de atletas e a consequente entrada em burn out também ela mais cedo do que desejável (Makarenko, 2001; Personne, 1987; Platonov \& Fessenko, 1994; Wilke, \& Madsen, 1990). Todo esse debate terá levado ao interesse de se desenvolver modelos de treino e periodização que permitissem em circunstâncias particulares a perpetuação dos atletas na carreira desportiva ao mais alto nível (Maglischo, 2003). Isto apesar da tendência para a diminuição da performance com o aumento da idade (Rubin \& Rahe, 2010). Mais ainda, os próprio processo de treino e de periodização para as provas mais curtas parece ser especialmente favorável à perpetuação dos nadadores em atividade, já que tem um caráter distinto do ponto de vista da carga interna e externa de treino das restantes especialidades (Maglischo, 2003; Silva et al., 2010).

A capacidade dos jovens para os esforços anaeróbios é inferior aos adultos. Isto deve-se a um menor nível da atividade da glicólise anaeróbia, já que a atividade das enzimas glicolíticas também é inferior nos jovens (Reis, 1996). A potência anaeróbia e a capacidade anaeróbia aumentam progressivamente durante o crescimento e maturação. Mais ainda, as curtas distâncias (50 e 100 m) requerem mais potência muscular e velocidade que atingem o pico máximo no término do salto pubertário, aproximadamente aos 16 anos (Silva et al., 2007). Consequentemente a possibilidade de evolução do rendimento nas provas de curta distância é maior do que nas provas de longa distância numa perspetiva de carreira desportiva.

Ao comparar-se a idade decimal com base no sexo, esta foi sempre significativamente superior nos nadadores do que nas nadadoras com exceção das provas de L50, L100 e L200. Mesmo nesses três casos os nadadores foram em média mais velhos do que as nadadoras. Com efeito, a literatura parece ser consistente nesta ideia de, ao longo das décadas, os nadadores tenderem a ser mais velhos do que os seus pares do sexo feminino para determinada distância/prova nadada (Lavoie \& Montpetit, 1986; Platonov \& Fessenko, 1994). Inclusive esta tendência internacional para as nadadoras serem mais novas do que os nadadores também é constatável na realidade da natação Portuguesa (Silva et al., 2006; 2007). Este facto está claramente relacionado com questões de índole maturacional onde os sujeitos do sexo feminino tendem a apresentar uma maior precocidade desenvolvimentista do que os sujeitos do sexo masculino (Duke, Liff \& Gross, 1980). Com efeito, este fenómeno transborda para o contexto da Natação Pura Desportiva já que as nadadoras são tidas como mais desenvolvidas maturacionalmente do que os nadadores para uma determinada idade cronológica durante o período pubertário (Lavoie \& Montpetit, 1986, Sokolovas, 1999). Este facto leva a que os modelos de plano de carreira das nadadoras considerem uma maior "precocidade" nas etapas de desenvolvimento desportivo do que nos nadadores (Silva et al., 2010).

Enquanto implicação prática para os técnicos no terreno emerge que a carreira desportiva dos nadadores velocistas é mais longa do que a dos fundistas. O pico de carreira desportiva deve ser planeado para ser atingida sensivelmente entre os 23 e os 27 anos em nadadores de provas curtas e entre os 19 e 24 anos para nadadores de provas longas. Assim sendo, o plano de carreira de um velocista pode e deve ser estruturado sem uma exagerada centralização no primado do rendimento durante os esca- 
lões de formação já que a carreira quer-se mais prolongada do que no caso dos nadadores de provas mais longas. A excessiva focalização no rendimento em escalões de formação pode-se revestir de uma pressão extra para o nadador, levando a quadros de sobretreino e/ou burnout inviabilizando o alcance do pico de carreira em idades próximas das verificadas nos nadadores de elite.

Comparando a idade de obtenção do pico de carreira por técnica de nado, para distâncias comuns (L100 vs C100 vs B100 vs M100 e L200 vs C200 vs B200 vs M200) a tendência é a mesma para ambos os sexos. Constata-se que as idades de pico para as provas de 200 metros são inferiores às provas de 100 metros pelos motivos explanados previamente. Para cada distância em apreço (100 metros e 200 metros) não se verificam diferencias substanciais entre as quatro técnicas de nado. Desta forma, enquanto implicação prática para os técnicos sugere-se que o plano de carreira a desenhar pode ser muito similar independentemente da especialização técnica que é feita por volta dos escalões de juvenil e júnior.

Dito isto, há a sublinhar que se podem configurar como limitações deste estudo: (i) a análise se cingir a nadadores de nível mundial, pelo que a sua extrapolação para outros níveis competitivos e/ou contextos deve ser efetuada com cautela; (ii) haver nadadores que participam em mais de uma prova, pelo que o número de inscrições não representa de forma válida o número de atletas participantes no calendário olímpico; (iii) a necessidade de futuramente se tentar uma abordagem determinística, compreendendo as hipotéticas relações entre a idade e a performance obtida ou outras características pertinentes, estabelecendo inclusive grupos de coorte por prova se isso for viável.

\section{CONCLUSÕES}

Pode-se então concluir que: (i) em ambos os sexos existe uma tendência para os nadadores das provas mais curtas serem mais velhos do que os das provas mais longas; (ii) a dispersão das idades é superior nas provas mais curtas e; (iii) por prova, os nadadores são mais velhos do que as nadadoras.

Assim sendo, os treinadores podem desenhar um plano de carreira sem um excesso de preocupação com o rendimento nos escalões de formação, evitando as principais causas de desistência de forma precoce da carreira desportiva, sem que se chegue a atingir o momento de máxima performance. Mais ainda, este estudo corrobora a necessidade de se considerar os pressupostos da maturação biológica e da respetiva precocidade das nadadoras em comparação com os nadadores.

\section{Agradecimentos:}

Nada declarado.

\section{Conflito de Interesses:}

Nada declarado.

\section{Financiamento:}

Nada declarado.

\section{REFERÊNCIAS}

Barbosa, T.M., Lima, V., Mejias, E., Costa, M.J., Marinho, D.A., Garrido, N., Silva, A.J., \& Bragada, J.A. (2009). A eficiência propulsiva e a performance em nadadores não experts. Motricidade, 5, 27-43.

Barbosa, T.M., Bragada, J.A., Reis, V.M., Marinho, D.A., Carvalho, C., \& Silva A.J. (2010). Energetics and biomechanics as determining factors of swimming performance: updating the state of the art. Journal of Science and Medicine in Sports, 13, 262-269.

Brown, T., \& Barrett, M.J. (1969). Tables for decimal age conversion by computer. Australian Dentist Journal, 14, 197-198.

Darisa, S.C. \& Farinha, F.K. (1995). Especialização precoce na natação e seus efeitos na idade adulta. Motriz, 1, 59-70 
Duke, P.M., Liff, I.F., \& Gross, R.T. (1980). Adolescents' self-assessment of sexual maturation. Pediatrics, 66, 918-920

Ivkovic, A., Bojanic, I., \& Ivkovic, M. (2001). The female athlete triad. Lijec Vjesn, 123, 200-206.

Lavoie, J.M., \& Montpetit, R. (1986). Applied Physiology of swimming. Sports Medicine, 3, 165-188.

Maglischo, E. (2003). Swimming fastest. Champaign, Illinois: Human Kinetics.

Makarenko, L. (2001). Natação - seleção de talentos $e$ iniciação desportiva. Porto Alegre: Artmed Editora.

Markuske, H. (1971). Tabulations on the age of children: advantages of decimal values. Dtsch Gesundheitsw, 26, 1797-1798.

Personne, J. (1987). Nenhuma medalha vale a saúde de uma criança. Lisboa: Livros Horizonte.

Platonov, V.N., \& Fessenko, S.L. (1994). Los sistemas de entrenamiento de los mejores nadadores del mundo. Volume I. Barcelona: Editorial Paidotribo.

Reis, V. (1996). Capacidade de Esforço, Crescimento e Treino. Revista Horizonte, 72, 12-15.

Rubin, R.T., \& Rahe, R.H. (2010). Effects of aging in Master swimmers: 40-years review and suggestions for optimal health benefits. Open Access Journal of Sports Medicine, 1, 39-44.

Sambanis, M., Kofotolis, N., Kalogeropoulou, E., Noussios, G., Sambanis, P., \& Kalogeropoulos, J. (2003). A study of the effects on the ovarian cycle of athletic training in different sports. Journal of Sports Medicine and Physical Fitness, 43, 398-403.

Silva, A.J., Marques, A.T., \& Costa, A.M. (2010). Identificação de talentos no desporto. Um modelo operativo para a natação. Alfragide: Texto Editora. Silva, A. J., Marinho, D., Carvalhal, I. M., Durão, M., Reis, V., Carneiro, A. \& Aidar, F. (2007) Análise da evolução da carreira desportiva de nadadores do género feminino utilizando a modelação matemática. Revista Brasileira Medicina Esporte, 13, 175-180.

Silva, A. J., Reis, V., Gudetti, L., Simões, P., Carneiro, A., Raposo, J. V. \& Baldari, C. (2006) Análise da Evolução da Carreira Desportiva de Nadadores do Sexo Masculino Utilizando a Modelação Matemática. Revista Treinamento Desportivo, 7, 50-57.

Sokolovas, G. (1999). Biological maturation of swimmers. In K.L. Keskinen, P.V. Komi \& A.P. Hollander (Eds.), Biomechanics and Medicine in Swimming VIII (pp. 315-319). Jyvaskyla: Gummerus Printing.

Stafford, D.E. (2005). Altered hypothalamic-pituitary-ovarian axis function in young female athletes: implications and recommendations for management. Treatment in Endocrinology, 4, 147-154.

Taylor, S, Stratton, G., Lees, A., Atkinson, G., \& MacLaren, D. (2001). Tethered swimming force and maturation stage in competitive age group swimmers Pediatric Exercise Science, 13, 272.

Weineck, J. (2002). Manual do treino ótimo. Lisboa: Instituto Piaget.

Wilke, K. \& Madsen, O. (1990). El entrenamiento del nadador juvenil. Editorial Stadium: Buenos Aires.

(cc) EY-No Todo o conteúdo da revista Motricidade está licenciado sob a Creative Commons, exceto quando especificado em contrário e nos conteúdos retirados de outras fontes bibliográficas. 